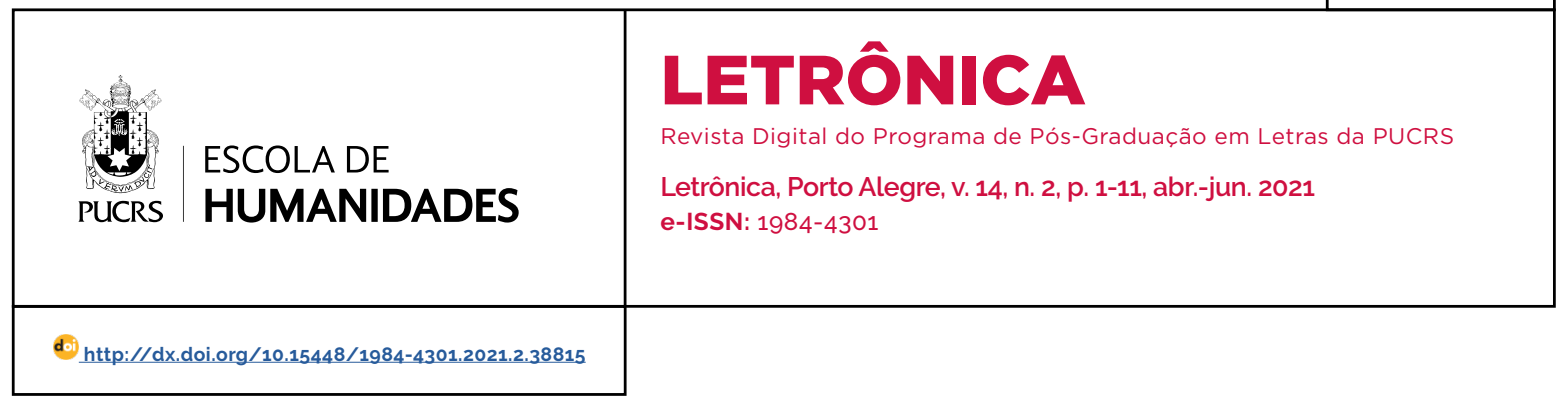

\title{
Descontinuidades entre aquisição da produção oral e aprendizagem da escrita
}

\author{
Discontinuities between oral production acquisition and learning how to \\ write
}

\author{
Leonor Scliar-Cabral ${ }^{1}$ \\ orcid.org/0000-0003-3163-5482 \\ leonorsc20@gmail.com
}

Recebido em: 07 ago. 2020. Aprovado em: 05 set. 2020. Publicado em: 10 agos. 2021.

\section{(c) (1)}

Artigo está licenciado sob forma de uma licença Creative Commons Atribuição 4.0 Internacional.
Resumo: Desenvolvem-se as premissas para o processamento cognitivo na alfabetização para a escrita, demonstrando que não predominam as semelhanças entre o processamento da produção oral e o da escrita, havendo muitas descontinuidades. Para facilitar a argumentação, resumo em um quadro, as descontinuidades que demonstram muitas das dificuldades com as quais se defrontam as crianças para se tornarem redatores competentes. Assim, enquanto a aquisição da fala ocorre de forma espontânea e compulsória, para aprender a produzir um texto escrito, é necessário o ensino sistemático por professores muito bem preparados e materiais pedagógicos de qualidade, ambos fundamentados pelos avanços das ciências que se ocupam da linguagem verbal. Enquanto a comunicação oral canônica ocorre face a face, na comunicação escrita ocorre a ruptura espaço-temporal, determinando um custo cognitivo enorme, pois quem escreve deve dominar o distanciamento necessário para imaginar para quem está escrevendo, quando e onde ele está para explicitar linguisticamente todas as informações que não estão à vista de quem vai ler o texto. Os limites da memória de trabalho, quando falamos, fazem com que as sentenças sejam breves e muito mais simples. O caráter de permanência do texto escrito possibilita a complexidade maior da sentença, com várias orações encaixadas, uso intensivo de anafóricos, inclusive lexicais. O contínuo da cadeia da fala oposto aos espaços em branco e aos contrastes entre as letras, na escrita é uma das grandes diferenças entre os dois sistemas, determinando uma das grandes dificuldades para quem está começando a aprender a escrever, inclusive porque o léxico mental fonológico da criança, muitas vezes discrepa em demasia das palavras escritas. Portanto é necessário trabalhar a nivel consciente a conversão dos fonemas em seu respectivo grafema em uma dada palavra.

Palavras-chave: Aquisição da linguagem oral. Aprendizagem da produção escrita. Descontinuidades. Ruptura espaço-temporal. Conversão fonema-grafema.

\begin{abstract}
I develop the premises for cognitive processing while learning early literacy for writing, demonstrating that the similarities between the oral production processing and that of writing do not predominate, since there are many discontinuities. To facilitate arguing, I summarize on a table the discontinuities, demonstrating many of the difficulties children face at in order to become competent writers. Thus, while the speech acquisition occurs spontaneously and compulsively, in order to learn how to produce a written text, systematic teaching by well-prepared teachers and quality teaching materials is necessary, both based on science advances that deal with verbal language. While canonical oral communication occurs face to face, in written communication there is a space-time rupture, determining an enormous cognitive cost, as the writer must have the necessary knowledge to imagine for whom he is writing, when and where he is to explain linguistically the information not at sight for the reader. The working memory limits, when we speak, impose shorter and much simpler sentences. The written text permanence ensures complex sentences, with several embedded
\end{abstract}


clauses, as well as intensive use of anaphors, including lexical ones. The speech chain continuum difference from the blank spaces and the contrasts between letters, in writing is one of the greatest one between the two systems, determining one of the great difficulties for those who are beginning writing learning, also because the child 's phonological mental lexicon, often differs too much from the written words. Therefore, it is necessary to teach the consciously phoneme conversion into their respective grapheme in a given word. Keywords: Oral language acquisition. Written production learning. Discontinuities. Temporal-spatial rupture. Phoneme-grapheme conversion

\section{Introdução}

"I... procuro promover a noção de que uma teoria da fala e uma teoria da leitura / escrita são inseparáveis e de que a validade de uma é mensurável, em não poucos trechos, pela adequação de uma à outra" (LIBERMAN, 1992, p. 167).

Neste artigo, desenvolvo as premissas para o processamento cognitivo na alfabetização para a escrita, ou seja, demonstrar que não predominam as semelhanças entre o processamento da produção oral e o da escrita, havendo muitas descontinuidades.

Para você compreender o que é escrever e como a criança aprende a fazê-lo é importante entender o que é falar e como uma criança adquire essa competência: ambos se incluem no campo da produção da linguagem verbal e partilham muita coisa em comum, particularmente, quando o sistema de escrita for alfabético, como o nosso. Mas eles têm, também, muita coisa diferente entre si que você precisa conhecer para conduzir da melhor forma o processo da aprendizagem de escrever. Por isso, organizei o Quadro 1, do qual, alguns itens desenvolverei neste artigo.

\section{A fala é adquirida e a escrita é aprendida}

Começa-se pelos seis primeiros itens do Quadro 1. A espécie humana foi biopsicologicamente programada para se comunicar através da fala, a fim de garantir a própria sobrevivência do indivíduo e da espécie (D'AQUILI, 1973). Sendo assim, a estrutura, o amadurecimento e o funcionamento do Sistema Nervoso Central e do periférico garantem que a espécie se comunique, de modo predominante, através de signos verbais orais. A preferência pela comunicação oral se deveu, entre outros motivos, pelo fato de ela poder ser usada à noite e a distâncias muito maiores do que a comunicação visual-gestual.

Os conhecimentos transmitidos de geração a geração, em grande parte, na forma de narrativas, eram registrados na memória permanente, ou de longo prazo, mas, à medida que as relações socioeconômicas foram se tornando mais complexas, essa maneira de registro se deparou com três grandes problemas: o volume de informações acumuladas se tornou muito grande, ultrapassando a capacidade de um só cérebro o armazenar e, quando o indivíduo morria, grande parte das informações ia com ele para o túmulo. Mas o que, realmente, forçou a invenção da escrita é a autonomia que o texto escrito assume em relação a quem o produziu, ao contrário da fala (é claro, antes das tecnologias de radiodifusão e de gravação): o texto escrito pode ser conduzido a lugares e tempos distantes. Isto veio suprir a necessidade de registrar o conteúdo, as quantidades e os preços das mercadorias que eram transportadas.

A invenção da escrita permite, então, o registro permanente da informação, a qual pôde ser transportada a espaços e tempos distantes. No entanto, para que funcione, é necessário que as pessoas que utilizem um dado sistema de escrita atribuam os mesmos significados básicos aos signos que o constituem, tarefa que cabe aos codificadores. O uso da escrita exige, também, a invenção de artefatos e de tecnologia para produzi-la, como instrumentos e o suporte onde escrever.

Ao contrário da fala, que só utiliza o próprio corpo, pois fomos biopsicologicamente programados para tal, os sistemas de escrita são uma invenção que surge tardiamente na trajetória humana e demanda a utilização de técnicas e de artefatos. 
Quadro 1 - Semelhanças e diferenças entre a produção oral e a escrita

\begin{tabular}{|c|c|c|c|}
\hline & Comum & Fala & Escrita \\
\hline Adquirida & & $x$ & \\
\hline Aprendida & & & $x$ \\
\hline Determinada biopsicologicamente & & $x$ & \\
\hline Usa o próprio corpo & & $x$ & \\
\hline Invenção cultural & & & $x$ \\
\hline Usa artefatos & & & $x$ \\
\hline Comunicação face a face & & $x$ & \\
\hline Ruptura espaço-temporal & & & $x$ \\
\hline Momentânea & & $x$ & \\
\hline Permanente & & & $x$ \\
\hline Contínuo da cadeia da fala & & $x$ & \\
\hline Espaços em branco entre palavras/contrastes entre letras & & & $x$ \\
\hline \multicolumn{4}{|l|}{ Processamento } \\
\hline 1. Inicio da mensagem ou texto: intenção pragmática & $x$ & & \\
\hline 2. Planejamento & $x$ & & \\
\hline 3. Modalização e entonação & & $x$ & \\
\hline 4. Da memória semântica à lexicalização e sintaxização & $x$ & & \\
\hline $\begin{array}{l}\text { 5. Atribuição do acento de intensidade pelo contraste entre silabas } \\
\text { mais fortes/mais fracas }\end{array}$ & & $\mathrm{x}$ & \\
\hline $\begin{array}{l}\text { 6. Atribuição do acento de intensidade pelos acentos gráficos ou } \\
\text { por conhecimentos fonológicos }\end{array}$ & & & $\mathbf{x}$ \\
\hline 7. Radicais no léxico ortográfico para irregularidades & & & $x$ \\
\hline 8. Juntura externa (sândi externo) & & $x$ & \\
\hline 9. Silabificação & & $x$ & \\
\hline 10. Sistemas alfabéticos: codificação & & & $x$ \\
\hline 11. Pontuação pela sintaxe & & & $x$ \\
\hline 12. Execução pelos gestos da fonação & & $x$ & \\
\hline 13. Execução pelos gestos manuais & & & $x$ \\
\hline 14. Monitoria online & $x$ & & \\
\hline 15. Monitoria online e revisão & & & $x$ \\
\hline \multicolumn{4}{|l|}{ Estrutura: Nivel do/a } \\
\hline 1. Texto ou mensagem & $x$ & & \\
\hline 2. Enunciado & & $x$ & \\
\hline
\end{tabular}




\begin{tabular}{|l|c|c|c|}
\hline 3. Parágrafo & & & X \\
\hline 4. Sentença (periodo) & $\mathbf{X}$ & \\
\hline 5. Padrão entoação & & $\mathbf{X}$ & \\
\hline 6. Pontuação & & & $\mathbf{X}$ \\
\hline 7. Oração & $\mathbf{X}$ & & \\
\hline 8. Frase & $\mathbf{X}$ & & \\
\hline 9. Núcleo & $\mathbf{X}$ & & \\
\hline 10. Morfema & $\mathbf{X}$ & & \\
\hline 11. Fonema & & $\mathbf{X}$ & \\
\hline 12. Grafema & & & \\
\hline 13. Letra & & & $\mathbf{X}$ \\
\hline 14. Traços fonéticos invariantes (com função distintiva) & & $\mathbf{X}$ & \\
\hline 15. Traços gráficos invariantes (sem função distintiva) & & & $\mathbf{X}$ \\
\hline
\end{tabular}

Fonte: Scliar-Cabral (no prelo, p. 12).

Esses primeiros argumentos já explicam por que a fala é adquirida de forma compulsória, espontânea e assistemática: por volta de um ano de idade, a criança está produzindo seus primeiros itens, em geral, uma reduplicação silábica, como 'nenê', 'papá', 'cocô' e 'mamá', sem a necessidade de ir à escola para aprender a falar: basta a interação com os demais que cuidam dela (LIBERMAN, 1992). Com os sistemas de escrita é diferente, particularmente, quando se trata de aprender a escrever que, ao contrário da fala na situação canônica face a face, implica escrever para um futuro leitor ausente no espaço e no tempo, além de que, embora o sistema de escrita do português brasileiro seja muito transparente para a leitura, apresenta mais irregularidades na escrita.

Então, não só como escrever tem que ser aprendido, mas, também são necessários alfabetizadores muito bem fundamentados e preparados para ensinar bem, apoiados em metodologias de ponta e que, pelo menos, saibam que a codificação não se reduz a conhecer as estruturas silábicas do PB! Acresce a necessidade de material pedagógico coerente com a fundamentação teórica.

\subsection{Comunicação face a face/Ruptura espaço-temporal}

Conforme mencionado brevemente, a comunicação verbal oral canônica se dá face a face, com os participantes não só compartilhando o mesmo espaço e tempo, como também muitas experiências empíricas do dia a dia. Ela dispensa, pois, a referência através de palavras do que é evidente pela própria situação, como se nomear a si próprio. As pessoas do discurso, ou seja, a $1^{\mathrm{a}}$ e a $2^{\mathrm{a}}$ pessoa, são quem fala e a quem a $1^{\text {a }}$ se dirige. Ambas podem falar sobre algo. Enquanto na comunicação oral canônica ou nos diálogos em discurso direto, transpostos à escrita, os referentes dos chamados dêiticos espaciais e temporais em relação às $1^{a}$ e $2^{\mathrm{a}}$ pessoas do discurso quando falam entre si (refiro-me aos pronomes demonstrativos e aos advérbios ou locuções adverbiais nessa situação) são evidentes, porque acompanhados de gestos de apontar, das expressões fisionômicas, da entoação e/ou porque o mesmo tempo e espaço é compartilhado pelos interlocutores, na comunicação escrita canônica ocorre a ruptura espaço-temporal: redator e leitor não compartilham o mesmo espaço e tempo, os quais necessitam ser contextualizados linguisticamente. Assim, nas cartas, bilhetes, avisos, oficios, é preciso explicitar o nome do destinatário 
e do remetente, além do local e data onde e quando se escreve. Existe um ditado colocado nos avisos das vendas e mercadinhos, onde se lê "Fiado só amanhã" que revela a intuição popular de que 'amanhã' não significa uma data precisa, a não ser que o texto esteja datado. O sentido de 'amanhã' no aviso das vendas e mercadinhos è 'nunca'.

Detenho-me nessa explicação porque uma das grandes dificuldades dos alunos, ao escrever, é colocar-se na posição do outro que vai ler o texto que eles estão escrevendo, em um outro espaço e tempo. Essa projeção é que vai permitir escrever de tal modo que o leitor possa entender o que o redator quis comunicar: isso deverá ser trabalhado desde o início, em nivel da criança. Ilustra-se o comentário, contrastando as duas situações.

Quadro 2 - Exemplo de comunicação face a face e de bilhete

\section{COMUNICAÇÃO COMUNICAÇÃO ORAL ESCRITA}

\begin{tabular}{|l|l|}
\hline $\begin{array}{l}\text { "Me alcança aquela } \\
\text { chave }\end{array}$ & Florianópolis, 15/12/12 \\
\hline que está ali, que estou & Querida Elê, \\
\hline saindo agora, & $\begin{array}{l}\text { Ontem, quase perdi } \\
\text { a hora da consulta } \\
\text { médica, }\end{array}$ \\
\hline para ir ao médico". & $\begin{array}{l}\text { porque havia esque- } \\
\text { cido a chave do carro } \\
\text { sobre a mesa. }\end{array}$ \\
\hline & $\begin{array}{l}\text { Mas deu tudo certo. } \\
\text { Espero que possamos } \\
\text { nos ver logo. } \\
\text { Grande abraço da Leo. }\end{array}$ \\
\hline
\end{tabular}

Fonte: Scliar-Cabral (no prelo, p. 14).

Quando você lê a comunicação oral, não consegue saber quem está falando nem para quem, assim como não sabe onde está a chave, nem quando a pessoa vai sair, referentes que são evidentes para os interlocutores naquela situação. Já na comunicação escrita você pode recuperar os referentes de 'perdi', 'havia esquecido' e 'Espero' (Leo), de 'possamos nos ver' (Elê e Leo), de 'ontem' (14/12/12) e de 'logo' (uma data a seguir próxima a 15/12/12).

\subsection{Momentânea/Permanente}

Conforme já mencionado, uma das propriedades da fala, na situação canônica, é a volatilidade: falamos e o(s) nosso(s) interlocutor(es) somente consegue $(m)$ reter alguma coisa do que dissemos em sua memória permanente, na forma de um resumo, muitas vezes distorcido, ou, por pouco tempo, na estação episódica da memória de trabalho, se os dados forem necessários a algum desempenho de atividade, os quais desaparecem, quando a ação for concluida. O texto escrito se caracteriza pela permanência. Isto garante a sua integridade e a socialização no espaço e no tempo (é claro que. para tal, ele necessita ser disponibilizado e que as pessoas saibam ler na língua em que foi escrito).

A memória de trabalho, conforme Uehara e Landeira-Fernandeza (2010, p. 32-33), é "um sistema de capacidade limitada que permite o armazenamento temporário e gerenciamento de informações [...]" composta "por quatro componentes: o primeiro deles é o executivo central, que desempenha determinadas funções", como atenção seletiva, flexibilidade mental, selecionar e executar planos e estratégias, alocar recursos em outras partes da memória de trabalho e evocar informações na memória de longo prazo. O segundo componente é a alça fonológica e o terceiro é o esboço visual-espacial.

\section{Baddeley (2000) adicionou ao modelo um quarto componente: o retentor episódico. Este é um componente de armazenamento temporário e com capacidade limitada, acessivel à consci- ência, que dialoga com a memória de longo- - prazo episódica e semântica na construção de representações integradas com base em uma nova informação (UEHARA; LANDEIRA- FERNANDEZA, 2010, p. 33).}

O fato de a capacidade da memória de trabalho ser muito limitada determina inúmeras consequências, uma delas já mencionada: os resumos registrados na memória permanente apresentam muitas distorções. Mas uma consequência importante é a de que o texto oral tem que se adequar a tais limites da capacidade de processamento: as sentenças são curtas, com poucas orações encaixadas, além de que as próprias condições da produção oral exigem as chamadas muletas 
de processamento, isto é, pausas vazias e plenas, como 'mmm', retificações, repetições e particulas de pedido de atenção dialógicas, como 'né?', 'viu?'. A sintaxe das orações no diálogo é omissa na superficie, particularmente nas respostas às perguntas "Qu", como nos diálogos transcritos abaixo:

- Quem quer comer goiabada?

- Eu.

- O que você está lendo?

- Clarice Lispector.

- Quando você retorna?

- Amanhã.

Todas as características da comunicação verbal oral acima, decorrentes principalmente da fugacidade do enunciado produzido, dos limites na capacidade da memória de trabalho, mas também do fato de os interlocutores estarem face a face, compartilhando o mesmo espaço e tempo, não caracterizam o texto escrito: sua permanência conduz à reflexão, ao atestado de nossos conhecimentos não só sobre o que estamos discorrendo e sobre a lingua escrita que estamos utilizando, como sobre nossa competência para pensar e para organizar o raciocínio.

Portanto, as características da comunicação verbal escrita, decorrentes da permanência, embora se encontrem em alguns tipos e gêneros da comunicação verbal oral, são: a) a coerência (FÁVERO; KOCH, 1983), mesmo em textos muito longos, como um livro, pois tal permanência permite ao redator, não só ter o plano (outline) à mão, para nortear a progressão das ideias, evitando a associação livre, quanto permite contínuas revisões do que já escreveu, até a revisão final (obrigatória para quem deseja produzir um bom texto escrito); b) a coesão e uma sintaxe mais complexa, com várias orações subordinadas na mesma sentença ou período: ao poder revisar o que escreveu, o redator pode corrigir os frequentes cochilos de concordância, permitindo que o(s) futuro(s) leitor(es) possa(m) recuperar as referências adequadamente, bem como pode alterar o uso dos operadores argumentativos, particularmente, das conjunções coordenativas e subordinativas; c) a introdução de novos universos de conhecimento e respectivo vocabulário: a permanência do texto permite o uso mais eficiente de estratégias como a de cruzar a informação dele extraída com os conhecimentos prévios baixados da memória permanente, o que possibilita inferenciar sentidos novos. Dadas essas características, somente após a invenção da escrita foi possível o advento da filosofia, da ciência e da história.

\subsection{Contínuo da cadeia da fala / Espaços em branco, contrastes entre letras}

Na produção oral, o que ocorre é a continuidade, ou dinâmica dos gestos articulatórios: executivos centrais coordenam na região frontal do cérebro os movimentos simultâneos de vários músculos para a obtenção de um mesmo alvo, a realização da sílaba. Não há comandos para a realização de cada fonema isolado, a não ser quando ele for, também, uma sílaba, de onde resulta a coarticulação, ou seja, a interferência reciproca entre segmentos adjacentes. Isto ficará mais claro para você se, diante do espelho, você observar o gesto de seus lábios ao tentar pronunciar a $1^{a}$ sílaba de pulha (sem chegar a emitir nenhum som) e ao tentar pronunciar a $1^{a}$ sílaba de pilha (sem chegar a emitir nenhum som). Você deve ter observado que, no primeiro caso, seus lábios fizeram o gesto arredondado, com o bico para frente e, no $2^{\circ}$ caso, os lábios ficaram distensos, sem bico. Isso ocorreu porque [u] é uma vogal arredondada e [i], não.

Podemos, pois, concluir que, na fala, não há contraste entre as unidades que realizam os fonemas. Um dos grandes feitos do ser humano foi descobrir que a silaba poderia ser desmembrada (os inventores dos sistemas alfabéticos tiveram a intuição de fonema): o primeiro passo dos inventores do protoalfabeto foi representar a consoante inicial das palavras do cananeu por um hieróglifo, como no exemplo de palavras que começassem por /b/ (do cananeu) e passaram a ser representadas pelo hieróglifo de uma casa, beit, em cananeu. Aos poucos, o hieróglifo que não representava mais a ideia de casa e, sim, o 
fonema /b/ que estivesse no início de qualquer palavra do cananeu, foi se tornando cada vez mais abstrato. No livro Sistema Scliar de Alfabetização - Fundamentos (SCLIAR-CABRAL, 2013), narro a história da evolução do alfabeto, mas deixo bem claro que, nos sistemas alfabéticos, como o nosso, uma ou duas letras, na função de grafemas, representam os fonemas, ambos com a função de distinguir o significado básico das palavras. Ao escrever, estamos convertendo fonemas em grafemas. Ao contrário da cadeia da fala, em que a realização dos fonemas em sons os mascara, por causa da imbricação entre uns e outros, na escrita, as letras que realizam os grafemas apresentam um contraste muito nítido entre si, salvo, quando, na manuscrita, elas se tornam quase ilegiveis. Um dos alvos na alfabetização para a escrita é ensinar de modo racional e sistemático a conversão dos fonemas em grafemas, particularmente em uma língua escrita considerada transparente como o PB. Outro alvo é ensinar a manuscrita de modo que os gestos que diferenciam as letras entre si sejam automatizados.

Na oralidade, também não há limites que demarquem onde terminam e onde começam as palavras Esse fenômeno se chama juntura externa fechada. No PB, quando a palavra terminar por /a/ átono e a seguinte começar por vogal átona, o /a/ final átono desaparece (é assimilado pela vogal seguinte), como em /'mala/ + /u'zada/ ('mala' + "usada") = /'malu'zada/. Se os dois fonemas forem idênticos, ocorre a crase, como em /'mala/ + /atírada/ ('mala' + 'atirada') = /'mala'tirada/. Se terminar em consoante e a seguinte começar por vogal, a consoante migra para o vocábulo seguinte, como em /'malas/ + / u'zadaS/ ('malas' + 'usadas') = /'malazu'zadaS/.

Quando dizemos "fazerumbolo" (usei a transcrição do português escrito para facilidade do leitor), ocorre a migração da consoante final 'r' de 'fazer' que gruda na vogal nasal do artigo indefinido, formando a sílaba 'rum' (não confundir com o valor que ela tem no nome da bebida, porque na fala de 'fazerumbolo', trata-se de uma cadeia contínua e as sillabas que a constituem são: fa-ze-rum-bo-lo). Houve, portanto, uma ressilabação, tornando opacas as fronteiras que delimitavam o final e o início de duas palavras, um dos maiores desafios à alfabetização.

É necessário compreender, pois, que não se escreve como se fala: a cadeia da fala é um contínuo, enquanto, na escrita, as palavras são separadas por espaços em branco. Na alfabetização para a escrita, o professor deve estar fundamentado para enfrentar essa dificuldade: trata-se de uma aprendizagem que deve ser feita de modo sistemático e, sobretudo, compreendendo as causas da dificuldade. A criança escreve 'zoio' porque em seu léxico mental fonológico foi assim que ela registrou o que ouviu, uma vez que, na cadeia da fala, em 'uzoio' (novamente estou usando a escrita canônica para facilidade do leitor), ocorre uma ressilabação e a marca do plural do artigo, gruda na vogal inicial 'ó'. Então, o professor, aos poucos, deverá ensinar que não se escreve como se fala e essa aprendizagem, obviamente, tem que ser explicita: não se adquire compulsória e espontaneamente como a fala.

Uma das evoluções dos sistemas alfabéticos de escrita foi a introdução dos espaços em branco entre as palavras, cujos limites, para a escrita, às vezes, são bastante arbitrários. Tomemos, como exemplo, o caso das palavras compostas, cujos termos ora são ligados por hífen, como em 'norte-americano', ora não, como em 'noroeste' e, frequentemente, por espaços em branco, como em "pés de galinha". No entanto, os espaços em branco, no PB, na leitura, ajudam a delimitar as classes sintáticas, como os artigos, as preposições, as conjunções, os pronomes, os verbos, substantivos, adjetivos e advérbios (salvo os compostos e locuções, em muitos casos). Na escrita, a delimitação da palavra por espaços em branco é um dos maiores problemas a serem enfrentados na alfabetização.

\section{Metalinguagem para a escrita: codificação dos fonemas independentes e dependentes do contexto fonológico}

Na perspectiva cognitiva para o aprendizado e ensino da alfabetização para a produção textual decorre que, em uma de suas etapas, trabalhe-se com a codificação dos fonemas independentes e dependentes do contexto fonológico. Isto se tornou possivel no português brasileiro escrito, 
porque as regras de codificação foram exaustivamente descritas (SCLIAR-CABRAL, 2003). A seguir, explica-se como se trabalha no PB escrito, com a conversão dos fonemas em grafemas.

Antes de executar os movimentos das letras, sejam elas manuscritas ou digitadas, quem escreve deve converter sua fala interior ao sistema de escrita que, no caso dos sistemas alfabéticos, implica traduzir os fonemas em grafemas, concretizados nas letras do alfabeto latino, adotado pelo PB escrito.

Primeiro, recordam-se os fonemas do português brasileiro, pois são eles que serão convertidos aos grafemas:

Quadro 3 - Quadro fonêmico das consoantes do PB

\begin{tabular}{|c|c|c|c|c|c|c|}
\hline & & $\begin{array}{l}\text { +ant } \\
\text {-cor } \\
\text { (labiais) }\end{array}$ & $\begin{array}{l}\text { +ant } \\
+ \text { cor } \\
\text { (anteriores) }\end{array}$ & $\begin{array}{l}\text {-ant } \\
+ \text { cor }\end{array}$ & $\begin{array}{l}\text {-ant } \\
\text {-cor } \\
\text {-post }\end{array}$ & $\begin{array}{l}\text {-ant } \\
\text {-cor } \\
+ \text { post } \\
\text { (posteriores) }\end{array}$ \\
\hline $\begin{array}{l}\text { +obstruinte } \\
\text {-cont } \\
\text { (oclusivas) }\end{array}$ & $\begin{array}{l}\text {-son (surdas) } \\
\text { +son }\end{array}$ & $\begin{array}{l}p \\
b\end{array}$ & $\begin{array}{l}\mathrm{t} \\
\mathrm{d}\end{array}$ & & & $\begin{array}{l}\text { k } \\
\text { g (galo) }\end{array}$ \\
\hline $\begin{array}{l}+ \text { +cont } \\
\text { (fricativas) }\end{array}$ & $\begin{array}{l}\text {-son } \\
\text { +son }\end{array}$ & $\begin{array}{l}f \\
v\end{array}$ & $\begin{array}{l}\mathrm{s} \\
\mathrm{z}\end{array}$ & $\begin{array}{l}\int \text { (chá) } \\
3 \text { (já) }\end{array}$ & & R (rosa) \\
\hline $\begin{array}{l}\text {-Obstruinte } \\
\text { +nasal }\end{array}$ & & M & $\mathrm{N}$ & & n (vinho) & \\
\hline $\begin{array}{l}\text { (+vocálico) } \\
\text { +lateral } \\
\text {-lateral } \\
\text {-cons (semivogais) }\end{array}$ & & & $\begin{array}{l}\text { l } \\
\text { r(caro) }\end{array}$ & & $\begin{array}{l}\Lambda \text { (velha) } \\
j \text { (pai) }\end{array}$ & $w(t e u)$ \\
\hline
\end{tabular}

Fonte: Lopez (1979), mais as semivogais, exemplos e termos comparativos, seguindo Mattoso Camara Jr. (1953).

No Quadro 3 o símbolo x, referente à variedade carioca descrita por Lopez, foi substituído pelo simbolo R, mais genérico, adotado por Mattoso Camara Jr., por cobrir todas as realizações nas variedades sociolinguísticas do $\mathrm{PB}$. Desdobramento das abreviaturas: cor = coronais; cont = contínuas; son = sonoras; cons = consoantes.

A tradução dos fonemas em grafemas deverá ser automatizada, tornando-se não consciente, se houver uma boa alfabetização para a escrita. A conversão pode ser independente do contexto, 0 que significa que o fonema sempre será convertido a um só grafema, seja qual for a posição que ocupar no vocábulo fonológico e / ou previsivel pela morfossintaxe e pela derivação morfológica. Mas há conversões irregulares, como / kiS/ que se converte num só grafema $<x>$ na palavra <óxido $>$. Uma grande fonte de dificuldades são os contextos competitivos como o fonema /s/ que pode se converter no grafema <c> em <acender $>$ ou $\langle\mathrm{SC}>$ na palavra <ascender>. 
As conversões dos fonemas aos grafemas, independentes do contexto fonológico, no $\mathrm{PB}$ escrito são: /p/, /b/, /t/, /d/, /f/, /v/, /m/, /n/, /n/, $/ \mathrm{l}, / \lambda / / \mathrm{r} /$ nos grafemas: $\langle\mathrm{p}\rangle$ (pato), $\langle\mathrm{b}\rangle$ (bato), $\langle\mathrm{t}\rangle$ (tato), $\langle$ d $\rangle$ (dato), $\langle\mathrm{f}\rangle$ (fato), $\langle\mathrm{v}\rangle$ (voto), $\langle\mathrm{m}\rangle$ (moto), $\langle\mathrm{n}\rangle$ (noto), $<$ nh $>$ (venha), $<l>$ (vela), $<$ lh $>$ (velha), $<$ r $>$ (Vera)

\subsection{Codificação dos fonemas} dependentes do contexto fonológico

A codificação do fonema dependente do contexto fonológico pode ocorrer em virtude: a) de o fonema que o suceder, como, por exemplo, o fonema /3/ que sempre se codifica no grafema $\langle j>$, antes de vogais posteriores, ou da semivogal /w/, como nos exemplos $\langle j u r a\rangle$, $\langle j o g o\rangle,\langle j o i a\rangle,\langle$ loja $\rangle$, $\langle j u n t o\rangle$, <rojões $>$, <janta>, <ajuizar $>$;

b) de o fonema que o suceder e/ou da posição que ocupa no vocábulo, ou sílaba, como, por exemplo, o fonema /s/ que sempre se codifica no grafema $\langle\mathrm{s}\rangle$, em início de vocábulo e antes de vogais posteriores, ou da semivogal / w/, como nos

Quadro 4 - Quadro fonêmico das vogais do PB

\begin{tabular}{|l|l|l|l|}
\hline +Orais & $\begin{array}{l}\text {-posterior } \\
\text {-arredondado } \\
\text { (anteriores) }\end{array}$ & $\begin{array}{l}\text { +posterior } \\
\text {-arredondado }\end{array}$ & $\begin{array}{l}\text { +posterior } \\
\text { +arredondado }\end{array}$ \\
\hline +alta & I & & U \\
\hline $\begin{array}{l}\text {-alta } \\
\text {-baixa }\end{array}$ & E & A & O \\
\hline +baixa & $\varepsilon$ (pé) & & J (pó) \\
\hline $\begin{array}{l}\text {-Orais } \\
\text { (nasais) }\end{array}$ & I & & U \\
\hline +alta & $\tilde{e}$ & $\tilde{a}$ & $\tilde{O}$ \\
\hline -alta & & & \\
\hline +baixa & & & \\
\hline
\end{tabular}

Fonte: Sistema vocálico do português brasileiro, conforme o modelo de Quicoli (1990), com acréscimo das vogais nasalizadas.

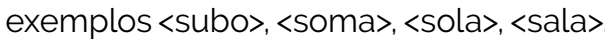

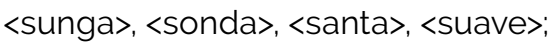

c) no caso das vogais átonas /i/, /e/; /u/, /o/, em posição átona final de vocábulo, conforme a variedade sociolinguística mais frequente no $\mathrm{PB}, / \mathrm{e} /$, /o/ não ocorrerão nesse contexto fonológico, postulando-se, então, o arquifonema |I|. $|\cup|$, respectivamente.
É necessário, portanto, explicar o que é o arquifonema. O que ocorre com as vogais átonas /e/. /i/; /o/, /u/ em posição final de vocábulo no PB? O traço [-alto] que distingue cada par e que é fundamental para distinguir significados, na posição tônica, como em 'furo'/'foro', vai para o espaço. É claro que você não pode indiferentemente dizer "Eu teve muita sorte 2 " ao invés de "Eu tive muita sorte 2 " ou "Eu fui ao furo levar os documentos",

2 Não está em transcrição fonológica, para facilitar a compreensão do leitor. 
ao invés de "Eu fui ao foro levar os documentos", mas, em posição átona final de palavra, tanto faz você dizer "U livru é interessanti3" quanto "O livro é interessante3", que não muda o significado.

Cientificamente, explicamos que o traço que distingue /e/ de /i/, /u/ de /o/ perdeu a função de distinguir significados e escolhemos o mais frequente, com letra maiúscula, como o arquifonema, a classe maior, que abrange ambos: /'tivl/, /'tevl/: /'forU/, /'furU/.

Em sentido estrito, isto resulta em um contexto competitivo, pois os respectivos grafemas tanto podem ser $<u>$ (forma marcada), <o> (forma default) ou <i> (forma marcada), <e> (forma default), mas a forma marcada é raríssima e usualmente vem seguida do grafema <s>, como em ônus, lápis. 0 que constitui um dos maiores problemas para o aprendiz é que nas variedades sociolinguísticas mais frequentes os fonemas que ocorrem são /u/, /i/, ocasionando um conflito entre eles e a respectiva codificação $\langle 0\rangle,\langle e\rangle$.

$\mathrm{O}$ arquifonema $|\mathrm{S}|$ abrange todos os fonemas, cuja função distintiva foi suspensa. Se fosse um carioca lendo a frase 'casas pretas', ele converteria o último grafema das duas palavras em $/ \int /$, mas, se fosse ler a frase 'casas brancas', converteria o último grafema da primeira palavra em /3/, porque, antes de uma consoante [+son], como /b/, ele assimila o traço [+son]; (antes do /p/ que é [-son], ele assimilou o traço [-son], assim como antes do silêncio). Na transcrição fonológica (entre barras obliquas), o arquifonema aparece com letra maiúscula: /'kasaS/. quando isolado, entre retas verticais paralelas: |S|.

Eu pergunto: mudou o significado da marca de plural quando eu, que sou gaúcha, leio, ou quando o carioca lê? NÃO, então a função distintiva de significado, que está provada no par /'asa/, /'aja/, codificado em <assa>, <acha> e /'aza/, /'a3a/, codificado em <asa $\rangle$, <haja $>$ foi SUSPENSA entre /s/, / /, e entre /z/, /3/ em final de silaba. 0 arquifonema $|S|$, no PB, abrange quatro fonemas, cuja função distintiva é suspensa, em final de silaba: /s/, /z/, / / / /3/.

O sistema de escrita do PB é muito transparente.
Podemos nos beneficiar do que estamos aprendendo para resolver uma das maiores dificuldades de ortografia. O arquifonema $|S|$ :

a) sempre se codifica no grafema $\langle\mathrm{s}\rangle$, quando for a marca do plural: <casas pretas $>$;

b) quando o vocábulo for oxitono ou monossílabo tônico, há duas possibilidades de codificação, $\langle$ S $>$ ou $\langle$ Z $>$ (contexto competitivo); aplicam-se, então, regras de derivação morfológica. Exemplos: nos monossilabos tônicos <quis> $\left(1^{\mathrm{a}}\right.$ e $3^{\mathrm{a}}$ pess. sing. do pret. perf. do ind. do verbo 'querer'); <fiz>, <fez> ( $1^{a}$ e $3^{a}$ pess. sing. do pret. perf. do ind. do verbo 'fazer'), como decidir sobre codificar $|S|:\langle s\rangle$ ou $<z>$ ? Pela derivação: ambos saem das formas primitivas <quise $\rangle$, <fize $>$ ( $2^{a}$ pess. sing. pret. perf. ind.). Basta memorizá-la e saberemos ortografar todas as formas derivadas: pret. perf. e m.-q.-perf. do ind. (<quisera >, < fizeram>); pret. imperf. e fut. do subj. (<quisesse $>$, < fizer $>$ ).

No sufixo que forma adjetivos e substantivos que indicam a origem ou nacionalidade de pessoas, animais ou coisas se usa o grafema <s> (como são monossílabos ou oxitonos terminados no fonema /'e/, seguido do arquifonema |S|, a vogal leva acento circunflexo na codificação): <burguês>, <chinês>. Nos sufixos <-ez>, <-eza> que formam substantivos abstratos, codifica-se $|S|$ no grafema $\langle Z>$ : $\langle$ viuvez>,

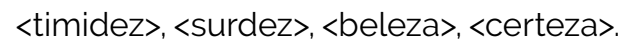

\section{Considerações finais}

Desenvolveram-se as premissas para o processamento cognitivo na alfabetização para a escrita, demonstrando que não predominam as semeIhanças entre o processamento da produção oral e o da escrita, havendo muitas descontinuidades.

Para facilitar a argumentação, resumiram-se, em um quadro, as descontinuidades que demonstram muitas das dificuldades com as quais se defrontam as crianças para se tornarem redatores competentes. Assim, enquanto a aquisição da fala ocorre de forma espontânea e compulsória, para aprender a 
produzir um texto escrito, são necessários o ensino sistemático por professores muito bem preparados e materiais pedagógicos de qualidade, ambos fundamentados pelos avanços das ciências que se ocupam da linguagem verbal.

Enquanto a comunicação oral canônica ocorre face a face, na comunicação escrita ocorre a ruptura espaço-temporal, determinando um custo cognitivo enorme, pois quem escreve deve dominar o distanciamento necessário para imaginar para quem está escrevendo, quando e onde ele está para explicitar linguisticamente todas as informações que não estão à vista de quem vai ler o texto.

Os limites da memória de trabalho, quando falamos, fazem com que as sentenças sejam breves e muito mais simples. O caráter de permanência do texto escrito possibilita a complexidade maior da sentença, com várias orações encaixadas, uso intensivo de anafóricos, inclusive lexicais

O contínuo da cadeia da fala oposto aos espaços em branco e aos contrastes entre as letras, na escrita é uma das grandes diferenças entre os dois sistemas, determinando uma das grandes dificuldades para quem está começando a aprender a escrever, inclusive porque o léxico mental fonológico da criança, muitas vezes discrepa em demasia das palavras escritas. Portanto é necessário trabalhar a nível consciente a conversão dos fonemas em seu respectivo grafema numa dada palavra.

\section{Referências}

BADDELEY, A. D. The episodic buffer as a new component of Working Memory? Trends in Cognitive Sciences, Cambridge, MA, v. 4, n. 11, p. 417-423, 2000

D'AQUILI, E. G. The biopsychological determinants of culture: An Addison-Wesley Module in Anthropology Reading. v. 13. Massachussets: Addison-Wesley, 1973

FÁVERO, L. L.; KOCH, I. G. Coesão e coerências textuais 11. ed. São Paulo: Ática, 2009.

LIBERMAN, A. M. The relation of speech to reading and writing. In: FROST, R.; KATZ, L. (ed.). Orthography, phonology, morphology and meaning. Amsterdam: North-Holland 1992. p. 167-178.

LOPEZ, B. A. The sound pattern of Brazilian Portuguese (Cariocan dialect). 1979. Tese (Doutorado) - University of California, Los Angeles, 1979.

MATTOSO CAMARA JR., J. Para o estudo da fonêmica portuguêsa. Rio de Janeiro: Org. Simões, 1953.
QUICOLI, A. C. Harmony, lowering and nasalization in Brasilian Portuguese. Lingua, Amsterdam, n. 80, p. 295331, 1990

SCLIAR-CABRAL, L. Principios do Sistema Alfabético do Português do Brasil. São Paulo: Contexto, 2003.

SCLIAR-CABRAL, L. Sistema Scliar de Alfabetização: Fundamentos. Florianópolis: Lili, 2013.

SCLIAR-CABRAL, L. Sistema Scliar de Alfabetização: Fundamentos para a Leitura. Florianópolis: Lili (no prelo).

UEHARA, E.; LANDEIRA-FERNANDEZA, J. Um panorama sobre o desenvolvimento da memória de trabalho e seus prejuizos no aprendizado escolar. Ciênc. cogn., Rio de Janeiro, v. 15, n. 2, p. 31-41, ago. 2010. Disponivel em: http://www.cienciasecognicao.org/revista/index. php/cec/article/view/375/187. Acesso em: 15 dez. 2017.

\section{Leonor Scliar-Cabral}

Doutora em Linguística pela Universidade de São Paulo (USP), em São Paulo, SP, Brasil. Pós-Doutora pela Universidade de Montréal. Professora Emérita, titular aposentada e professora colaboradora do Programa de Pós-Graduação em Linguística na Universidade Federal de Santa Catarina (UFSC), em Florianópolis, SC, Brasil. Fundadora, ex-presidente e atual sócia honorária da International Society of Applied Psycholinguistics. Alimenta o maior banco mundial em aquisição da linguagem, o CHILDES; criou o Sistema Scliar de Alfabetização.

\section{Endereço para correspondência}

Leonor Scliar-Cabral

Universidade Federal de Santa Catarina

Centro de Comunicação e Expressão

Rua Eng. Agronômico Andrei Cristian Ferreira, s/n

Trindade, 88040-900

Florianópolis, SC, Brasil

Os textos deste artigo foram revisados pela Poá Comunicação e submetidos para validação da autora antes da publicação 